\title{
Similarities and Differences among Semantic Behaviors of Japanese Adnominal Constituents
}

\author{
Kyoko Kanzaki and Qing Ma and Hitoshi Isahara \\ Communications Research Laboratory \\ 588-2, Iwaoka, Iwaoka-cho, Nishi-ku, Kobe, 651-2492, Japan \\ $\{$ kanzaki|qma|isahara\}@crl.go.jp
}

\begin{abstract}
This paper treats the classification of the semantic functions performed by adnominal constituents in Japanese, where many parts of speech act as adnominal constituents. In order to establish a formal treatment of the semantic roles, the similarities and differences among adnominal constituents, i.e. adjectives and "noun + NO (in English "of + noun")" structures, which have a broad range of semantic functions, are discussed. This paper also proposes an objective method of classifying these constructs using a large amount of linguistic data. The feasibility of this was verified with a selforganizing semantic map based on a neural network model.
\end{abstract}

\section{Introduction}

Pustejovsky (Pustejovsky, 1995) proposed the theory of a generative lexicon as a framework by which meanings of words are expressed in one unified representation. This kind of generativity would be very useful for NLP, especially if it is applicable to the complex semantic structures represented by various modification relations. In our previous research on adjectives (Isahara and Kanzaki, 1999) we used Pustejovsky's theory to classify adjectives in Japanese. In this paper we take the first steps in a similar classification of the Japanese "noun + NO" construction. Bouillon (Bouillon, 1996) applied this theory to the adnominal constituent of mental states. Saint-Dizier (Saint-Dizier, 1998) discussed adjectives in French.

Isahara and Kanzaki (Isahara and Kanzaki, 1999) treated a much wider range of phenomena of adnominal constituents. They classified the semantic roles of adnominal constituents in Japancse, where many parts of speech act as adnominal constituents, and discussed a for- mal treatment of their semantic roles. In their research, adnominal constituents, mainly adjectives which function as adverbials, are discussed. The present paper describes the similarities and differences among adnominal constituents, i.e. adjectives and "noun $+\mathrm{NO}^{1}$ (in English "of + noun")" structures which have a broad range of semantic functions. This paper proposes an objective method for classifying these structures using a large amount of linguistic data. The feasibility of this was verified with a self-organizing semantic map based on a neural network model.

In section 2, we explain the semantic functions performed by "noun + NO." In section 3 , we discuss how we can semi-automatically obtain and classify examples of adjectives and "noun + NO" structures which have similar semantic functions. In section 4 , we introduce a self-organizing semantic map to verify the result of this classification. In section 5 , we discuss similarities and differences between adjectives and "noun + NO" structures.

\section{The Diversity of Semantic Relations between "noun + NO" and their Head Nouns}

Among Japanese adnominal constituents, " noun + NO" represents a wider range of semantic relations than other adnominal constituents. Therefore, "noun + NO" does not always behave like the other adnominal constituents. In previous work, some researchers have analyzed semantic relations between the noun in the "noun + NO" structure and its head noun (Shimazu et al., 1986). Here, we show several examples that demonstrate the diversity of the se-

\footnotetext{
"NO" is a Japanese postpositional which can represent a wide range of semantic relations. It is similar to "of" in English.
} 
mantic relation between "noun $+\mathrm{NO}^{\text {" struc- }}$ tures and their head nouns shown in their research.

DENWA NO SECCHI

DENSHA NO TUUKIN

ASHITA NO DEITO

BILU NO MAE

KODOMO NO NAMAE

BAKUHATSU NO GEN'IN

KAISHI NO JIKOKU

HEYA NO BANGOU

KANOJO NO NOUTO BENGOSHI NO SMITH SAN installation of the telephone commuting by

a date for train tomorrow in front of the building the name of the child the cause of the explosion the starting time the number of the room

her note

Mr. Smith, the lawyer

These semantic relations between "noun + NO" structures and their head nouns are different than those between other adnominal constituents, e.g. adjectives and their head nouns. However, some "noun + NO" behavior is similar to the behavior of adjectives and nominal adjectivals. In these cases "noun $+\mathrm{NO}$ " seems not to differ semantically from adjectives and nominal adjectivals. Let us consider the English examples:

financial world / world of finance ("ZAIKAI") industrial center / center of industry ("SANGYOU NO CHUUSHIN")

In this case "noun + NO" need not be distinguished from an adjective with respect to semantic behavior. However, in the following examples it is necessary to distinguish them from one another.

global center / center of the globe

("SEKAI NO CHUUSHIN ( CHIKYUU NO CHUUSHIN")

We do not have a discrimination criteria that automatically recognizes whether a "noun + NO" structure is similar in its semantic behavior to that of adjectives or not. We have attempted to gather, semi-automatically, nouns in the "noum + NO" structure which behave like adjectives.
3 The Exploration of the Similarities of Semantic Functions of "noun + NO" Structures and Adjectives. (The Method for this Research)

\subsection{The Basic Concept}

There is one case in which the meanings of adnominal constituents are semantically similar to the features of the referents of their head nouns, e.g. adnominal constituents represent the concrete contents of their head nouns. Let us consider the Japanese phrase "KANASHII KIMOCHI (sad feeling)" and "YOROKOBI NO KIMOCHI (feeling of delight)" as examples.

\begin{tabular}{ccc}
$\begin{array}{c}\text { KANASHII } \\
\text { adjective }\end{array}$ & $\begin{array}{c}\text { KIMOCHI } \\
\text { noun } \\
\text { (fad) }\end{array}$ & $\begin{array}{c}\text { (feeling) } \\
\text { sad feeling }\end{array}$ \\
$\begin{array}{ccc}\text { YOROKOBI } & \text { NO } & \text { KIMOCHI } \\
\text { noun } & \text { postp. } & \text { noun } \\
\text { (delight) } & \text { (of) } & \text { (feeling) }\end{array}$ \\
\multicolumn{2}{c}{ feeling of delight }
\end{tabular}

NB: The English gloss of the "noun + NO" examples should be read from right to left.

One meaning of "KIMOCHI (feeling)" represents the semantic element <mental state>. In the above examples, the adjective, "KANASHII (sad)", and "noun + NO", "YOROKOBI NO (of delight)", represent the concrete contents of their head noun "KIMOCHI (feeling)", i.e. they also represent the mental state: "feeling". Therefore, even though they belong to different parts of speech (adjective/noun), they must be classified in the same semantic category since both carry the same meaning. Neither the adjective, "KANASHII (sad)", nor the "noun + NO", "YOROKOBI NO (of delight)", can appear in predicative position without changing their meaning.

However, if adnominal constituents do not share the same semantic concept as their head noun, they cannot represent the contents of head nouns. The examples below demonstrate this.

$\begin{array}{ccc}\begin{array}{c}\text { KANASHII } \\ \text { adjective }\end{array} & \text { KIMOCHI } & \text { noun } \\ \text { (sad) } & \text { (feeling) } \\ \text { JOHN } & \text { NO } & \text { KIMOCHI } \\ \text { noun } & \text { postp. } & \text { noun } \\ \text { (John) } & \text { (of) } & \text { (feeling) } \\ \text { John's feeling }\end{array}$


In the above examples, the noun in "noun + NO", "JOHN", does not include the concept, $<$ mental state $>$, so it cannot represent the content of "KIMOCHI (feeling)." The adjective, "KANASHII (sad)", and the noun in the "noun + NO", "JOHN" do not embody the same concept and have a different semantic relation with their head noun. We cannot find the semantic similarities between "KANASHII (sad)" and "JOHN" that we could between "YOROKOBI NO (of delight)" and "KANASHII (sad)." We focus on the phenomena where adnominal constituents represent the concrete contents of their head nouns. This makes it possible to identify adjectives and "noun + NO" structures which are similar in semantic behavior to the referents of their head nouns. These expressions are extracted semi-automatically from large corpora.

\subsection{How to Extract the Necessary Information}

When we collect words which have some similarities, it is difficult to select the semantic axis for classification by making use of only the co-occurring words. In collecting similar words, some previous research took not only cooccurring words but also the context of these words into account (Grefenstette, 1994). One of the important points of our analysis is the introduction of the distinct semantic elements that both "noun + NO" structures and adjectivals (adjectives and nominals) have in common with their head nouns. We wanted to ascertain the similarities between "noun + NO" and other adnominal constituents based on these common semantic elements. For this reason, we used the semantic relations, in which adnominal constituents represent the concrete content of their head nouns, as a key to classification. We automatically ${ }^{2}$ extracted these relations from one year of newspaper articles from Mainichi Shimbun (1994), 100 novels from Shincho publishers and 100 books covering a varicty of topics. We used the following procedure to extract the necessary information.

Step 1) Extract from the corpora, all nouns which are preceded by the Japanese expression "TOIU" which is sornething like "that" or "of." "TOIU + noun (noun that/of ...)" is a typical Japanese expression which introduces some in-

\footnotetext{
${ }^{2}$ Only Step 3 ) is done manually.
}

formation about the referent of the noun, such as apposition. Therefore, nouns found in this pattern may have their content elucidated by means of their modifiers.

Step 2) Extract from the corpora, all "noun + NO" structures, adjectives and nominal adjectivals which modify the nouns extracted in step 1 .

NB, the relationships between adnominal constituents and their modified nouns extracted here include not only representations of the contents of the noun, but also other various relations.

Step 3) Extract "noun + NO" structures, adjectives and nominal adjectivals which represent the contents of the referents of the modified nouns. Step 3 is done manually.

Step 4) In order to find the distribution of their semantic categories and analyze the semantic similarities between "noun + NO" and other adnominal constituents in each semantic category, we clustered the modified nouns automatically. This clustering was based on sets of similar adnominal constituents which represent the content of the referent of the modified noun.

\section{The Semantic Map of the Modified Nouns Constructed by the Self-Organizing System of the Neural Network Model}

We can gather similar modified nouns when we classify the modified nouns according to the similarities of the adnominal constituents, because in our data both adnominal constituents and their modified nouns have the same semantic elements in common that we mentioned above.

We attempted to construct the Semantic Map of the modified nouns gathered by the abovementioned method by using the self-organizing system of the neural network model (Ma et al., 2000). We suppose that both modified nouns and adnominal constituents have common semantic elements when adnominal constituents represent the concrete content of their head nouns. If this is true, nouns with similar meanings are located near each other on the semantic map, self-organized by the similarities of semantic elements among the adnominal constituents. The result of our experiment verified this supposition (Figure 1). The nouns with a similar 
meaning are located near each other on the map and we could divide the distribution of the modified nouns into seven categories (Figure 2).

Each group, i.e. the "mental state" group, "state/ situation" group, "characteristics" group, "range/ area" group, "viewpoint/ standpoint" group, "aspect" group, and "others," represents a meaning held in common by nouns in the group. Mental state can be further divided into the state of emotion, mood and intention. As we analyze the adnominal constituents in each category of modified nouns, we can find the possibility of the co-occurrence of an adnominal constituent with a head noun. Table 1 shows examples of adjectives and nouns in "noun + NO" structures in each group.

Table 1: List of adjectives and "noun + NO" Structures

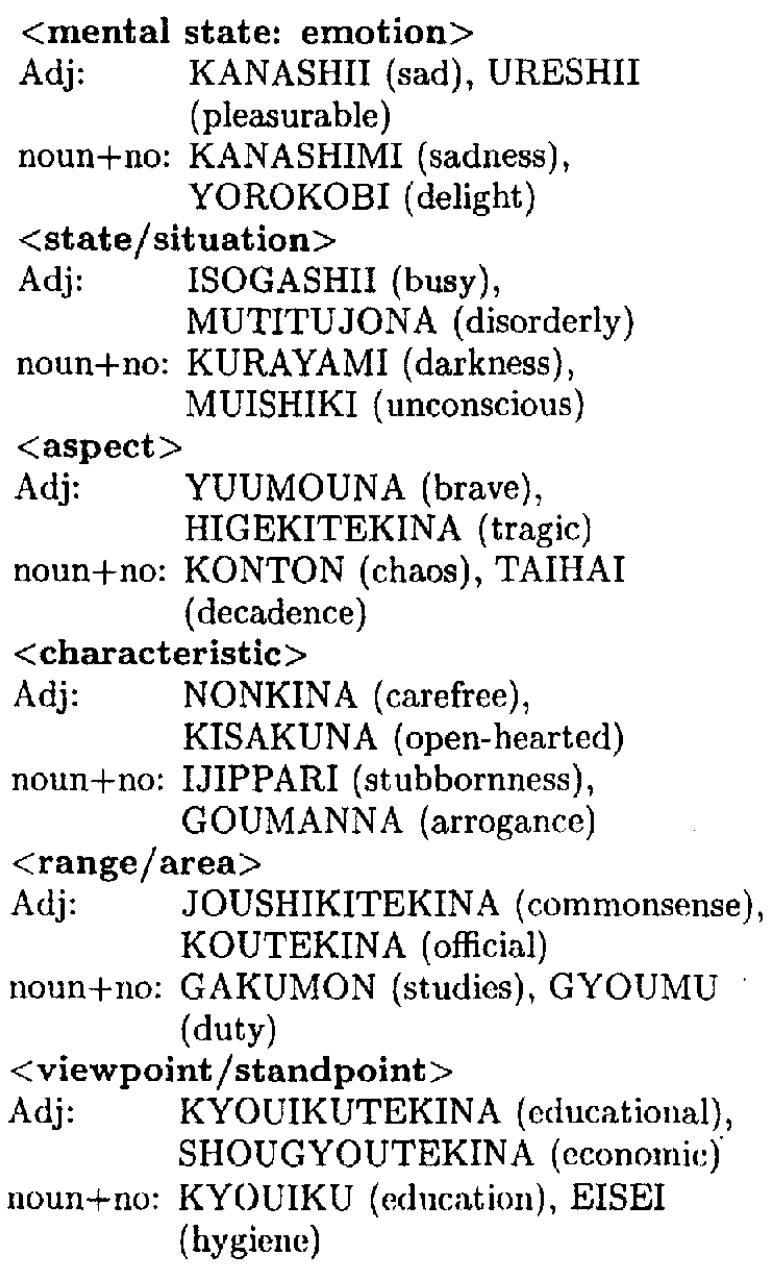

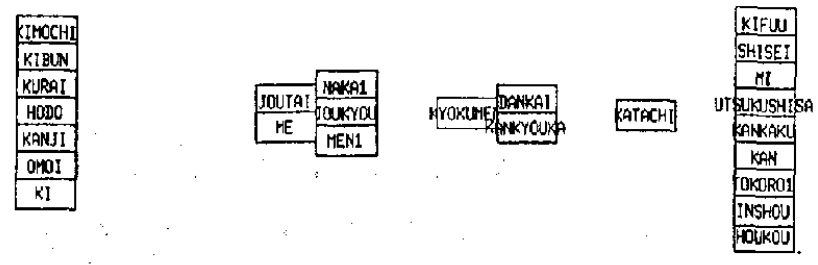

rousu
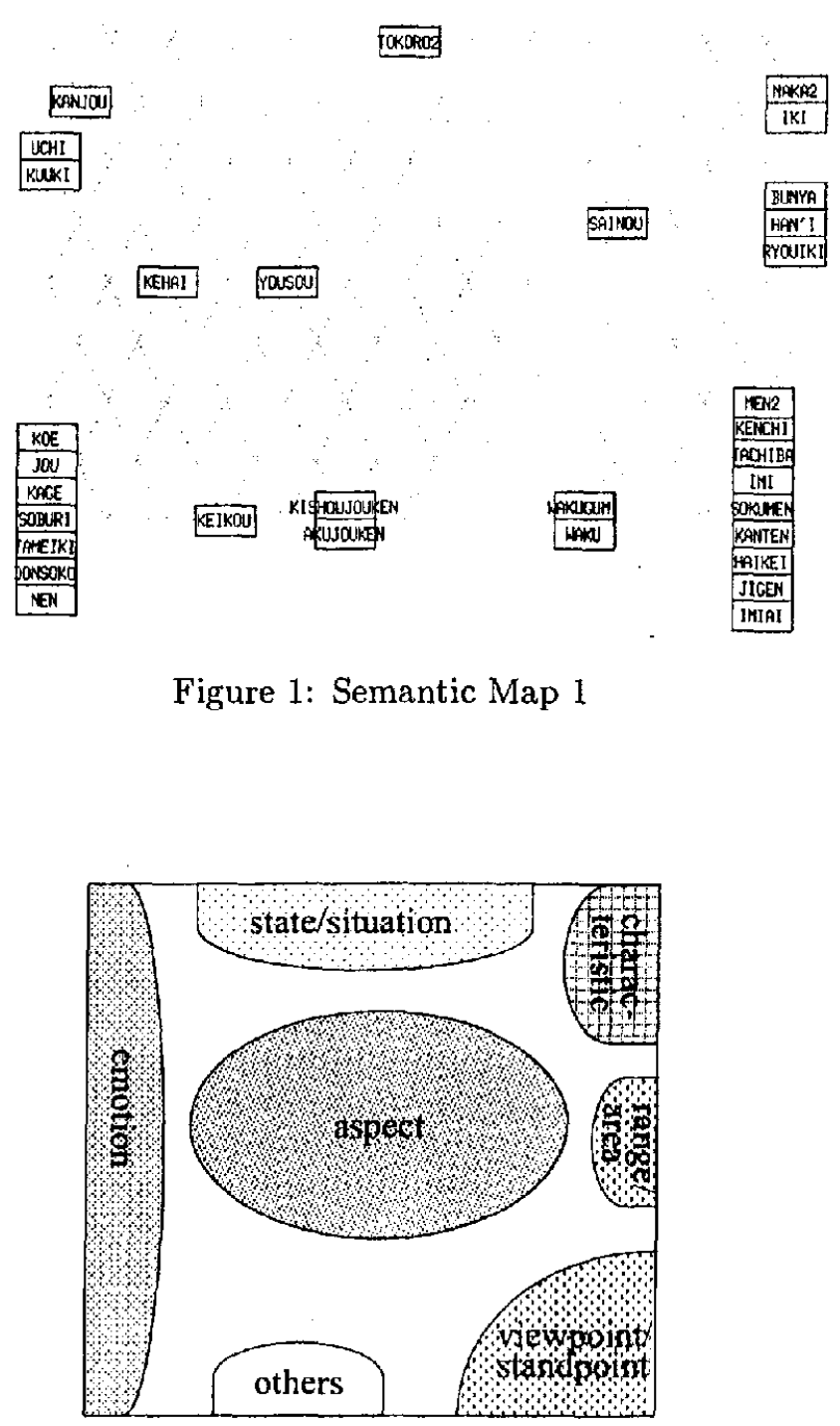

Figure 2: Semantic Map 2

In the mental state, state/situation, aspect and characteristics groups, adjectives appear more frequently than "noun + NO" constructions. These are simple adjectives. In the rauge/area and viewpoint/standpoint groups, 
"noun + NO" structures appear more frequently than simple adjectives. Nominal adjectivals derived from nouns plus the suffix "TEKIna" appear often with these noun groups. Most nouns in the groups "mental state: emotion", "state/situation" and "characteristics", contain abstract nouns which represent emotions, situations or characteristics. There are few concrete nouns. However, in the groups "range/area" and "viewpoint/standpoint", there are many concrete nouns which represent natural phenomena, organizations or professional domains and few abstract nouns. We can find differences among "noun + NO" structures, that is, there are adjectives which behave like nouns semantically and there are nouns which behave semantically like adjectives.

\section{The semantic behavior of the "noun + NO" structure which is similar to that of adjectives}

\subsection{Types of nouns in the "noun + NO" structure}

As we mentioned in section 3 , we extracted the "noun + NO" structures which have the same semantic element, along with similar adjectives, from large corpora. For example,

$$
\begin{array}{cc}
\text { KIKEN_NA } & \text { JOUTAI } \\
\text { (dangerous) } & \text { (situation) } \\
\text { dangerous situation }
\end{array}
$$

In this case "dangerous" represents the state concretely.

$$
\begin{gathered}
\text { MIKETTEI NO JOUTAI } \\
\text { (indecision) (of) (situation) } \\
\text { a situation of indecision }
\end{gathered}
$$

In this case, the "MIKETTEI NO (of indecision)" also represents the state concretely. Here, both "KIKENN_NA (dangerous)" and "MIKETTEI NO (of indecision)" have the same semantic element "state" in common. We find that a "situation" can be represented by both an adjective and the "noun + NO" structure. When "MIKETTEI NO (of indecision)" cooccurs with modified nouns other than "situation", it mostly represents the semantic notion, e.g. "MIKETTEI NO MONDAI (a problem of indecision)", and so on. That is, "MIKETTEI NO (of indecision)," represents the situation of a problem. So we see that "MIKETTEI NO (of indecision)" is in itself like an adjective.

On the other hand, "KUMORI NO (cloudiness)" behaves sometimes like an adjective and sometimes not.

KUMORI NO JOUTAI
(cloudiness) (of) (state)
a state of cloudiness

The semantic behavior of "KUMORI NO (of cloudiness)" is like the behavior of adjectives in that the cloudiness represents the state as "KIKEN_NA (dangerous)," however, "KUMORI NO (of cloudiness)" does not always represent the state of the referent of the modified noun though "MIKETTEI NO (of indecision)" always represents that. "KUMORI (cloudiness)" is a natural phenomenon which can be pointed to concretely. For example,

$\begin{array}{llr}\text { KUMORI } & \text { NO } & \text { NISSU } \\ \text { (cloudiness) } & \text { (of) } & \text { (amount) }\end{array}$

\section{WA 4 GATU NI SITEWA IJOU DA.}

The amount of cloudiness is unusual for April.

In this example, "KUMORI NO (of cloudiness)" modifies "NISSU (the amount)," and does not represent a state but the possessor of the amount.

As the examples of "MIKETTEI NO (of indecision)" and "KUMORI NO (of cloudiness)" show, there are nouns which have the same properties as adjectives intrinsically (e.g. "MIKETTEI (indecision)"), and other nouns which intrinsically have different properties from adjectives (e.g. "KUMORI (cloudiness)"). So, it is important to consider the properties of the noun in "noun + NO" when we analyze the "noun + NO" which behaves semantically like an adjective. Such an analysis enables us to find the situation in which they act like adjectives. We classified nouns in "noun + NO" structures into three types based on what the nouns refer to. Nouns from the last category, 3), are similar to adjectives semantically. As adjectives do not represent concrete objects or verb-like notions, nouns from these categories only occasionally resemble adjectives. 
Noun Categories:

1) nouns which refer to concrete objects. (like rain, book, science, and so on)

2) nominalizations (like decision, work, and so on)

3) nouns which belong to neither 1) nor 2), e.g. abstract nouns and so on.

As our corpora contain mainly newspaper articles, many compound nouns appear. Since the last word in a compound noun determines the properties of the whole word, we focus on the last word in classifying them.

Table 2 contains examples of the noun categories. "KOUGYOU TOSHI (industry city)" is an example of a compound noun where the last word "TOSHI (city)" determines the properties.

Table 2: Some "noun + NO" constructions with "impression"

1) nouns which refer to concrete objects

$$
\begin{array}{cc}
\text { KOUGYOU TOSHI, } & \text { HINOKI } \\
\text { (industry city) } & \text { (cypress) }
\end{array}
$$

2) nominalizations

$$
\begin{array}{cc}
\text { SOKUBAKU, } \\
\text { (restriction) }
\end{array} \quad \text { (improvement) }
$$

3) nouns which belong to neither 1) nor 2)

MUTONTYAKU, JAKUSHOU
(carelessness)

In the following section, we analyze the similarities and differences of the semantic behavior of "noun + NO" structures and adjectives. Firstly, we describe the case in which the semantic behavior of "noun + NO" is similar to that of adjectives and then we mention the case in which the semantic behavior of "noun + NO" is different from that of adjectives. Secondly, we analyze several types of nouns in "noun + NO" which behave like adjectives, even though nouns in "noun + NO" are not intrinsically similar to adjective types.

\subsection{The differences of semantic behavior between nouns in "noun + NO" and adjectives}

For example, "KANASHII (sad)", "URESHII (pleasurable)", "ZANNEN_NA (regrettable)", "KANASHIMI NO (of sadness)", "YOROKOBI NO (of delight)" and so on, modify nouns such as "OMOI (thought)", "KANJI (emotion)" and so on. Using a set of adnominal constituents, such as "KANASHII (sad)", "URESHII (pleasurable)", "ZANNEN_NA (regrettable)", as keys for classification, we can classify the modified nouns, "OMOI (thought)", "KANJI (feeling)" and so on, into the same group. Then we can find a semantic relationship between these adnominal constituents and their head nouns, in this case, <emotion>. In the following, we describe the similar and differing semantic behaviors of "noun + NO" and other adjectives in the same semantic category. As we described in the previous section, we extract sets of "noun + NO" structures and adjectives from data which was sorted semantically. Words in each set represent the semantic substance of the similar nouns which they modify. Therefore, their semantic categories are similar. Examples of modified nouns of a similar semantic category and their modifiers which have a semantic category similar to that of the nouns are listed in Table 3. Included are some "noun + NO" examples which though cooccurring with <mental state> nouns are not classified as such themselves. There are many adjectives and nominal adjectivals which can modify nouns in Table 3, such as "AWARENA (poor)", "IJIRASHII (moving)" and "HOKORASHII (triumphant)." Some "noun + NO" structures are semantically similar to these adjectives since they represent the contents of the emotion, e.g. "FUKAI NO KAN (sensation of displeasure)" and "YOROKOBI NO KIMOCHI (feeling of delight)." Most nouns in these "noun + NO" structures in Table 3 are classified into "mental activity by humans" by the "Word List Classified by Semantic Principles ${ }^{3}$." "Noun + NO" structures, which have this kind of semantic category, are similar to adjectives and nominal adjectivals, as both represent the content of the human mind. We call this semantic cat-

\footnotetext{
${ }^{3}$ This list was compiled by The Natural Language Research Institute, Tokyo.
} 
Table 3: The modified nouns and adjectives, nominal adjectivals, and "noun + NO" collected in the semantic category, $<$ mental state $>$

\section{Modified nouns \\ KANJI (feeling), KAN (sensation), OMOI (thought), KI (intention), NEN (inclination), KIMOCHI (mind), KIBUN (mood), KANJO (emotion), JO (passion) \\ Adjectives and nominal adjectivals AWARE_NA (poor), IJIRASHII (moving), HOKORASHII (triumphant), KINODOKU_NA (unfortunate), SHIAWASE_NA (happy), ZANNEN_NA (disappointing), URESHII (pleasurable), ... and so on.}

"Nouns" in the "noun + NO" structure a) mental activity KANASHIMI (sadness), FUKAI (displeasure), SHITASHIMI (familiarity), ZOUO (abhorrence), GAMAN (endurance), KOUKAI (regret), YOROKOBI (joy), MANZOKU (satisfaction), RAKUTAN (disappointment), IGAI (unexpected), ... and so on.

b) nominalizations HOSHIN (self-defense), CHIKUZAI (moneymaking), INTAI (retirement), HIHAN (criticism), HIYAKU (rapid progress), ... and so on

egory created by these adnominal constituents and their modified nouns "Feeling."

On the other hand, some adnominal relationships concerning a mental state can only be represented by "noun + NO" structures, such as "HOSHIN NO KIMOCHI (desire of defending one's own interest)," "CHIKUZAI NO NEN (thought of moneymaking)" and "INTAI NO KIMOCHI (idea of retirement)." Event nouns are mainly used in these "noun + NO" structures. Adnominal modifying relations of "nominalization + $\mathrm{NO}+$ mental state_noun" structures represent an intentional mental state.
This kind of intentional mental state cannot be expressed by adjectives. We call this semantic category "Intentional mental state."

We discussed two types of semantic representations above, i.e. Feeling and Intentional mental state. Feeling can be represented by adjectives and "noun + NO" structures. However, Intentional mental state can be represented only by "noun + NO" structures. From the standpoint of the characteristics of the modified nouns (they represent human mental states), these two mental activities (Feeling and Intentional mental state) are similar, even though there are differences in whether the activity is intentional or not. However, from the standpoint of the selection of an adnominal relationship in the surface structure, whether the activity has active intention or not will be the deciding factor for the selection between adjectives and "noun + NO" structures.

\subsection{The case where the semantic behavior of "noun + NO" structures is similar to that of adjectives}

Here we focus on nouns whose properties are unlike those of adjectives, i.e. the nouns which refer to concrete objects, verbal notions and so on.

(1) In the case where "noun $+\mathrm{NO}$ " represents characteristics, there is some overlap between the semantic behavior of adjectives and "noun + NO" structures.

I) The case where the noun in "noun + NO" is a compound noun

Let us compare "noun $+\mathrm{NO}$ " with adjective usage.

$\frac{\text { MUKUCHI_NA }}{\text { (reticent) } \quad \text { INSHOU }}$

\section{GA TUYOI JOHN-SAN WA $\cdots$}

John who makes a reticent impression …

\begin{tabular}{llr} 
KOUGYOUTOSHI & NO & INSHOU \\
\hline (industry city) & (of) & (impression)
\end{tabular}

GA TUYOI KAWASAKISHI WA... 
KAWASAKI city which gives a strong impression of an industrial city ${ }^{4}$.

In the previous two examples, the differences between "noun + NO" and adjectives depend only on whether the nouns they modify represent a person or a city where both head nouns have characteristics in common. However, "KOUGYOUTOSHI (industry city)" does not always have the same semantic relation to the modified noun, as seen in the following example:

\begin{tabular}{ccc} 
KOUGYOUTOSHI & NO & YUKYUTI \\
\hline (industry city) & (of) & $\begin{array}{c}\text { (vacant land) } \\
\text { NI TYAKUMOKU. }\end{array}$
\end{tabular}

They noticed the vacant land in the industrial city.

In this example, the semantic relation between "KOUGYOUTOSHI NO (of industry city)" and "YUKYUTI (the vacant land)" indicate the relation of possession so that it is not a semantic relation that adjectives can represent. When the modified nouns are abstract nouns that represent the property ("INSHOU (impression)" or "SEIKAKU (characteristics)" etc.), or instances of the concrete nouns in compound nouns ("KAWASAKI SHI (KAWASAKI city)"), the semantic function of compound nouns in "noun + NO" constructions represent the characteristics of the referent of the modified nouns as adjectives do.

a) Modified nouns which are abstract nouns that represent a property.

\begin{tabular}{lll} 
KOUGYOUTOSHI & NO & IMEJI \\
\hline (industry city) & (of) & (image)
\end{tabular}

GA OOKII.

The image of an industrial city is strong.

\begin{tabular}{lrr} 
KOUKYUUHIN & NO & INSHOU \\
\hline (high quality item) & (of) & (impression)
\end{tabular}

\section{GA TUYOI SHANERU}

(with) CHANNEL the impression of a high-quality item is strong.

\footnotetext{
${ }^{4}$ Note that some words which are nouns in Japanese (e.g. industry, high quality) must be translated as adjective in English (c.g. industrial, high-quality)
}

b) Modified nouns which represent instances of the concrete nouns in compound nouns

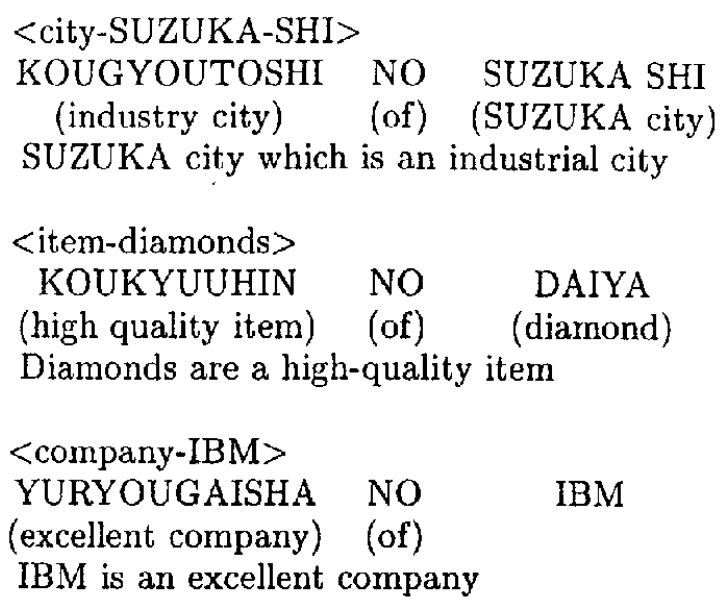

When the modified noun is an instance of the last word of the modifying compound noun, the semantic function of the whole compound noun is similar to that of adjectives because, in this type of compound, we focus on the adjectival semantic element. For example, "KOUGYOU (industry)" in "KOUGYOUTOSHI (industry city)", "KOUKYUU (high-quality)" in "KOUKYUUHIN (high quality item)", and "YUURYOU (excellent)" in "YUURYOUGAISHA (excellent company)" are adjectival.

II) the nouns that refer to the concrete object in "noun + NO"

Originally the nouns that refer to a concrete object or event do not have the same meaning as adjectives, however, they have similar semantic behavior to that of adjectives in the following case.

$$
\begin{aligned}
& \text { KARE WA } \frac{\text { OTONASHII }}{\text { (mild) }} \text { (disposition) } \\
& \text { NO MOTINUSHI DA. }
\end{aligned}
$$

He has a mild disposition.

The "mild" represents the characteristic (disposition). In the following examples the "noun $+\mathrm{NO}$ " also indicate the characteristics of something. 


\section{KODOMOTACHI WA ... MASSUGU \\ NOBIRU

$\begin{array}{llr}\text { HINOKI } & \text { NO } & \text { INSHOU } \\ \text { (HINOKI-tree) } & \text { (of) } & \text { (impression) }\end{array}$ \\ GA ARIMASHITA.}

These children give the impression of a HINOKI-tree which grows straight.

\section{KAGAKUGAISHA TOIU KOTODE IPPAN NO HITO NIWA

$\begin{array}{llr}\text { KANKYOUOSEN } & \text { NO } & \text { INSHOU } \\ \begin{array}{c}\text { (environment pollution) } \\ \text { impression of environmental pollution }\end{array} & \text { (impression) }\end{array}$

\section{GA TUYOKATTA.}

Ordinary people have a strong impression of environmental pollution from the chemical company.

The impression the children make is of a "HINOKI (HINOKI-tree)" and the impression the chemical company makes is of "KANKYOUOSEN (environmental pollution)". These "noun + NO"structures represent the characteristics of children and a company in same manner that the adjective "mild" indicates his characteristic. In these examples, nouns in "noun + NO" represent objects and events and so on, i.e. "HINOKI-tree" and "environmental pollution" these nouns ordinarily do not behave like adjectives. That is, the adjective "mild" can represent a characteristic directly, however, these nouns in "noun + NO" cannot represent the characteristics of something directly. We cannot say "that children are HINOKI-tree" and "the company is the environmental pollution" while we can say "He is mild." That is, in this case, "noun + NO" cannot appear in the predicative position with this meaning. When we show the characteristics of something by using nouns that refer to concrete objects and events, we need to specify the modified nouns which indicate the characteristics like "impression," "disposition" and so on.

(2) "Noun + NO" can represent quantification. Some adjectives can also represent quantification.

NIHON NO.HASHIMOTO SHUSHOU NO TEIAN WA AIKAWARAZU

$\frac{\text { TYUUSHOUTEKI_NA }}{\text { (abstract) }}$ IKI

NI TODOMATTA. The suggestion of the Japanese prime minister, Hashimoto, was still in an abstract state.

\section{HUSAINO HIRITU GA KAKEI NI TOTTE KIKEN_NA IKI NI TASSHITEIRU. (dangerous) (level)}

The rate of debt has reached a dangerous level for the household budget.

The suggestion of the Japanese prime minister is at an "abstract" level on the "concreteabstract" scale and the rate of debt is at a "dangerous" level on the "safety-dangerous" scale. The level of concreteness and safety is represented by adjectives. On the other hand, the nouns that refer to concrete objects and verbal notions also represent a level by inference from the context. We can infer the scale from the contextual situation. For example,

\section{KOUNIN KOUHO WA \\ UWASA NO DANKAI \\ the stage of rumor}

DA GA BORUGA SHI

Though it is completely at the stage of rumor, the candidate for the succession is $\mathrm{Mr}$. Borgar $\cdots$

\section{SHUSHOU GAWA WA $\cdots$}

(the prime minister and his staff)

\begin{tabular}{llr} 
ENZETU & NO & IKI \\
\hline (speech) & (of) & (level)
\end{tabular}

WO KOERARENAKATTA. Though the prime minister and his staff said "we will specify the guidelines of the government proposal during the election", after all it was still at the level of speech.

\section{GIJUTUTEKINIWA

\begin{tabular}{lrr} 
KANSEI & NO & IKI \\
\hline (completeness) & (of) & (level)
\end{tabular}

NI TASSHITEITA.

It reached a level of completeness, technically. 
In the above case, we do not have a semantic element of actual "talk" in the "rumor" or "speech" meaning nor a semantic element "event" in the "completeness" meaning, but we have the level of "rumor" on the "truth-rumor" scale, the level of "speech" on the "statementspeech" scale and the level of "completeness" on the "incompleteness-completeness" scale. The nouns that refer to concrete objects and verbal actions are similar to adjectives when they represent a level in context.

\section{Conclusion}

In this paper, we discussed the similarities and differences among adnominal constituents, i.e. adjectives and "noun + NO" structures which have a broad range of semantic functions. Nouns and adjectives differ in part of speech, but they sometimes have similarities when used adnominally. In such a case, we need not distinguish them from each other semantically. We investigated explicit criteria to detect similarities and differences between nouns and adjectives in adnominal usage. This research was verified by using large corpora and a self-organizing mapping system based on the neural network model. In future work, we will attempt to systematically classify words used adnominally according to the semantic behavior of adnominal constituents following the theoretical insights of Pustejovsky.

\section{Acknowledgment}

We would like to thank Catherine Macleod of New York University and Kiyotaka Uchimoto of the Communications Research Laboratory for their invaluable help in writing this paper.

\section{References}

P. Bouillon. 1996. Mental State Adjectives: the Perspective of Generative Lexicon. In Proc. of COLING96.

G. Grefenstette. 1994. Corpus-Derived First, Second and Third-Order Word Affinities. In Proc. of the EURALEX' 94 .

H. Isahara and K. Kanzaki. 1999. Lexical Semantics to Disambiguate Polysemous Phenomena of Japanese Adnominal Constituents. In Proc. of ACL99.

Q. Ma, K. Kanzaki, M. Murata, K. Uchimoto, and H. Isahara. 2000. Construction of a Japanese Semantic Map using SelfOrganizing Neural Network Model. In 6th Annual Meeting of the Association for Natural Language Processing, Japan. (will appear).

J. Pustejovsky. 1995. The Generative Lexicon. The MIT Press.

P. Saint-Dizier. 1998. A Generative Lexicon Perspective for Adjectival Modification. In Proc. of the Conference volume2 in 36th Annual Meeting of the Association for Computational Linguistics and 17th International Conference on Computational Linguistics (COLING-ACL '98).

A. Shimazu, S. Naito, and H. Nomura. 1986. Analysis of semantic relations between nouns connected by a Japanese particle "no". Keiryo Kokugogaku (Mathematical Linguistics), 15(7). (in Japanese). 